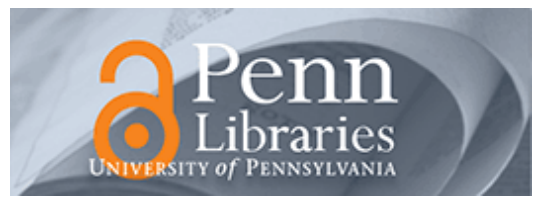

University of Pennsylvania

ScholarlyCommons

Finance Papers

Wharton Faculty Research

4-2015

\title{
Could Flood Insurance be Privatised in the United States? A \\ Primer
}

Erwann Michel-Kerjan

University of Pennsylvania

Jeffrey Czajkowski

University of Pennsylvania

Howard Kunreuther

Follow this and additional works at: https://repository.upenn.edu/fnce_papers

Part of the Finance and Financial Management Commons, and the Insurance Commons

\section{Recommended Citation}

Michel-Kerjan, E., Czajkowski, J., \& Kunreuther, H. (2015). Could Flood Insurance be Privatised in the United States? A Primer. The Geneva Papers on Risk and Insurance - Issues and Practice, 40 (2), 179-208. http://dx.doi.org/10.1057\%2Fgpp.2014.27

This paper is posted at ScholarlyCommons. https://repository.upenn.edu/fnce_papers/99

For more information, please contact repository@pobox.upenn.edu. 


\title{
Could Flood Insurance be Privatised in the United States? A Primer
}

\begin{abstract}
Since 1968, homeowners' flood insurance in the United States has been mainly provided through the federally-run National Flood Insurance Program (NFIP). The Flood Insurance Reform Act of 2012 raises the possibility of moving coverage to the private sector, assuming the market can price this risk effectively and that premiums reflect risk. This paper provides the first large-scale quantification of riskbased premiums for over 300,000 residences prone to either storm surge or inland flooding using commercially developed probabilistic catastrophe models, and compares these premiums with those currently charged by the NFIP. Our findings reveal significant differences between the two. In some areas, the NFIP charges prices that are more than 15 times the pure premium, while other areas are charged up to three times less than the pure premium. The paper discusses the market and policy implications of these findings.
\end{abstract}

\section{Keywords}

insurance pricing, catastrophe model, flood insurance, NFIP

Disciplines

Business | Finance and Financial Management | Insurance 
The Geneva Papers, 2014, 00, (1-30)

\title{
Could Flood Insurance be Privatised in the United States? A Primer
}

\author{
Erwann Michel-Kerjan, Jeffrey Czajkowski and Howard Kunreuther \\ Center for Risk Management and Decision Processes, Wharton School, University of Pennsylvania, Huntsman Hall, \\ Suite 500, 3730 Walnut Street, Philadelphia, PA 19104, U.S.A. \\ E-mail: erwannmk@wharton.upenn.edu
}

\begin{abstract}
Since 1968, homeowners' flood insurance in the United States has been mainly provided through the federally-run National Flood Insurance Program (NFIP). The Flood Insurance Reform Act of 2012 raises the possibility of moving coverage to the private sector, assuming the market can price this risk effectively and that premiums reflect risk. This paper provides the first large-scale quantification of risk-based premiums for over 300,000 residences prone to either storm surge or inland flooding using commercially developed probabilistic catastrophe models, and compares these premiums with those currently charged by the NFIP. Our findings reveal significant differences between the two. In some areas, the NFIP charges prices that are more than 15 times the pure premium, while other areas are charged up to three times less than the pure premium. The paper discusses the market and policy implications of these findings.
\end{abstract}

The Geneva Papers (2014) 0, 1-30. doi:10.1057/gpp.2014.27

Keywords: insurance pricing; catastrophe model; flood insurance; NFIP

Article submitted 5 August 2013; accepted 14 July 2014; advance online publication, 29 October 2014

\section{Introduction}

If recent weather events are any indication as to what the United States will face in the future, the country has entered a new era of catastrophes. Owing to increased population and more exposed assets in hazard-prone areas, we can expect more devastating and costly natural disasters in the coming years. Changes in climate patterns are likely to exacerbate this trend due to sea level rise and increased flooding from more frequent precipitation events and possibly more intense hurricanes and related storm surges.

Hurricane Sandy, which made landfall in the highly populated New York/New Jersey region in October 2012, is the latest reminder of America's vulnerability to natural disasters, causing an estimated US\$72 billion in damage. Compared with victims of Hurricane Katrina in 2005, those at risk from Sandy were better prepared for the disaster, with evacuation plans and more investment in risk-reduction measures in place. Still, a 2013 report by the Mayor's office of New York City estimates that less than 20 per cent of residential buildings in areas inundated by Sandy had flood insurance. ${ }^{1}$ Those who were insured received insurance claim payments from the federally run National Flood Insurance program (NFIP).

\footnotetext{
${ }^{1}$ City of New York (2013).
} 
The NFIP, administered by the U.S. Federal Emergency Management Agency (FEMA), provides flood insurance to 5.6 million policyholders across the country and covers more than US\$1.2 trillion in assets, a 250 per cent increase since 1990, corrected for inflation. ${ }^{2}$ In the aftermath of the 2005 and 2008 hurricane seasons, the programme had to borrow US\$18 billion from the U.S. Treasury to pay an historical level of claims, leading to calls for reforming this programme by the U.S. Congress, FEMA and flood hazard and insurance experts alike. Between 2010 and 2012, FEMA conducted a policy review of possible reform options. ${ }^{3}$ One of FEMA's reforms options, which is the focus of this paper, is the privatisation of residential flood insurance. ${ }^{4}$ The logic behind this would be to offset some of the taxpayers' de facto exposure to flood risk: when Sandy hit in 2012, the NFIP had to borrow another US\$9.7 billion from the U.S. Treasury to pay its claims-totalling US\$27 billion in debt today.

Given that residential flood insurance is provided by the private market in several other countries including Australia, France, Germany, Japan and the U.K., ${ }^{5}$ this is ostensibly not an unreasonable reform option for the United States. This possible increased role of the private insurance sector to cover flood risk was also part of the U.S. National Flood Insurance Reform Act of 2012.

A key research question related to the privatisation reform option is to determine the amount that private insurers would charge if they were to underwrite residential flood insurance on a large scale in the United States. To our knowledge, this research has not been undertaken. It is an important question to address as conventional wisdom holds that the private market would systematically charge more than the NFIP. There are also issues associated with affordability of coverage that need to be addressed in order for insurers to consider entering this market.

Central to this question is whether private insurers are able to measure homeowners' individual flood risk more effectively than FEMA currently does and thus charge a premium that would more accurately reflect individual exposures. FEMA has the responsibility for mapping communities participating in the NFIP and designates high to minimal flood zone risks within these mapped communities. Whether private insurers are able to measure and price flood risk better than FEMA is worth analysing, since as of 2008, 50 per cent of FEMA's 100,000 flood risk maps were outdated, primarily due to limited resources at their disposal. $^{6}$

This paper focuses on how premiums are determined that are considered to be actuarially fair rather than examining the well-known subsidies that have been part of the programme since its inception in 1968. The NFIP prices their entire portfolio by calculating the average

\footnotetext{
${ }^{2}$ Michel-Kerjan (2010).

${ }^{3}$ The four options FEMA discusses in its 2011 report are: keeping the programme as is (status quo), modernising the programme in its current form, privatising flood insurance, and transferring the responsibility of flood insurance from the federal government to the communities. See FEMA (2011) for more details. The Flood Insurance Reform Act of 2012 (also known as Biggert-Waters 2012, or BW12), modified in 2014, phased in risk-based premiums over time for policies currently subsidised by the programme.

${ }^{4}$ The NFIP covers both residential and small business lines but we focus here on residential insurance only, specifically single-family residential. NFIP commercial coverage in Texas represents less than 5 per cent of the total NFIP policies in force.

${ }^{5}$ Clark (1998); von Ungern-Sternberg (2004); Thieken et al. (2006); Botzen and van den Bergh (2008).

${ }^{6} \mathrm{GAO}(2008)$.
} 
historical losses and at a rather aggregate geographical level. It also lacks elevation data for a number of structures it insures. We contend that a much more granular approach based on probabilistic risk assessment incorporating data from past events coupled with future flood scenarios at a given location is required to determine the pure premium for a given structure. The technology for undertaking these computations currently exists. We compare the results of this more comprehensive analysis with premiums currently charged by the NFIP.

The paper is organised as follows. The next section briefly discusses the operation of the NFIP, how it prices flood insurance and the challenges the programme currently faces. In the subsequent section we characterise a methodology based on advanced probabilistic catastrophe modelling by the private sector that determines at an individual property level the risk-based premium for providing a homeowner with flood risk coverage. We then apply this methodology to over 300,000 residences in two Texas counties: Travis (inland; riverine flood risk) and Galveston (coastal; primarily storm surge flood risk) as a pilot study. Our research team partnered with the large data provider CoreLogic and the reinsurance company Swiss Re to access hazard, exposure and vulnerability data for these individual residences in these two counties.

We selected Texas for the analysis because it is a state with one of the largest number of NFIP flood insurance policies in force in the U.S. and has suffered from severe flood events in recent years. For example, in 2008 Hurricane Ike made landfall in Texas as a category 2 hurricane and triggered the third largest NFIP payment in the history of the programme (after Hurricanes Katrina in 2005-US $\$ 16$ billion-and Sandy in 2010-US\$8 billion) with US $\$ 2.6$ billion in flood insurance claims. Moreover, we were able to look both at surge risk on the coast and inland riverine flooding within Texas.

The penultimate section compares unloaded premiums (i.e. pure premiums generated by the probabilistic catastrophe flood model) and full premiums (that incorporate different loading factors) with those charged by the NFIP for single-family residences in Travis and Galveston Counties in Texas. Given that the NFIP is federally run and does not seek to make a profit, some might expect the programme to charge lower premiums, all things being equal. But a key finding of this analysis is that there are a variety of cases where it would be, on average, less expensive for residents to purchase flood insurance from private insurers than from the NFIP and not only in the designated low-risk flood zones.

We find for instance, that 90 per cent of residents in FEMA's V zones in Galveston (high risk on the coast; see definition of zones in the appendix) are currently charged by the NFIP a pure premium that is higher on average than what the probabilistic risk assessment indicates should be the case. We also find that many other residents are currently potentially undercharged by the NFIP on average, not necessarily because of a subsidy they receive, but as a result of inaccurate flood hazard maps and the way FEMA prices insurance through classes of risk at a very large level of aggregation. Notably, on the coast where storm surge flooding seems poorly integrated into FEMA's flood hazard maps, many residences across all flood zones are not paying the risk-based price. As we explain in more detail later in the paper, these results are likely a consequence of (a) outdated and non-comprehensive flood maps and (b) the averaging of flood insurance rates across large areas in a given flood zone based only on average loss. They do not take well into account local geographic flood risk differences and the potential for truly catastrophic events. The final section concludes with a discussion of the market and policy implications of these results, including the impact of risk-based premiums on the demand for flood insurance. 


\section{NFIP pricing of flood insurance coverage}

This section provides an overview of the history of the NFIP, its current scope, and some of the challenges it faces today. We also describe how the NFIP prices flood insurance.

\section{Origin and operation of the National Flood Insurance Program (NFIP)}

The NFIP was developed in 1968 because, ever since the severe Mississippi floods of 1927, the private insurance industry believed flood risk was uninsurable due to adverse selection and the possibility of massive losses. ${ }^{7}$ Additionally, there were concerns about their ability to correctly price the product, because the level of sophistication in hazard assessment was quite limited back in the 1960s compared with what it is today. ${ }^{8}$

This lack of coverage by the private sector led the federal government to provide significant relief to victims of Hurricane Betsy in 1965 and led to a discussion as to whether the federal government could develop a federal flood insurance programme. ${ }^{9}$ A government programme could potentially be successful because it would have funds to initiate the programme, pool risks more broadly, subsidise existing homeowners to maintain their property values while charging actuarial rates to new construction, and tie insurance to land-use changes that might lower risks. The programme would also have the capacity to spread losses over time by borrowing money from the federal government to compensate for a deficit, something private insurers cannot do. ${ }^{10}$ Thus, the main goal of the NFIP was to provide flood insurance to those in hazard-prone areas with the understanding that there might still be truly exceptional events for which the programme would have to borrow money from the federal government.

Flood insurance premiums are determined by FEMA, which manages the programme. Over 95 per cent of NFIP policies are written through the Write Your Own (WYO) Program, which allows participating property/casualty insurance companies in the private market to write and service NFIP's standard one-year flood insurance policy. ${ }^{11}$ The insurance companies bear no risk and are compensated for writing policies and settling claims. The NFIP provides insurance up to a maximum limit for residential property damage, now set at US\$250,000 for building coverage and US $\$ 100,000$ on contents coverage. Some additional coverage is offered by private insurers above these limits for residential property owners, although this represents a small percentage (less than 5 per cent approximately) of total residential coverage. There is also private flood insurance coverage in the lender-placed market, 160,000 policies on average at any point in time. ${ }^{12}$

The scope of the NFIP has increased significantly over the past decades, mainly due to a combination of more people living in hazard areas, ${ }^{2,13}$ more of them buying insurance and

\footnotetext{
${ }^{7}$ Overman (1957); Gerdes (1963).

${ }^{8}$ Considerable progress has been made in catastrophe modelling, GIS and risk map digitalisation in the past 20 years and has improved the risk assessment process considerably as discussed in the section 'Determination of flood insurance pure premiums using catastrophe modelling'.

${ }^{9}$ Kunreuther et al. (1978); Burby (2001).

${ }^{10}$ See Michel-Kerjan (2010) for an analysis of the operation of the programme between 1968 and 2009.

${ }^{11}$ Michel-Kerjan and Kousky (2010).

${ }^{12}$ Dixon et al. (2007).

${ }^{13}$ For instance, according to the U.S. Census data, the population in Texas increased from 9.5 million in 1960 to nearly 26 million in 2011 and the population of Florida from 2.5 million in 1950 to 19 million in 2011, a large portion of those people being exposed to flood hazard.
} 
their purchasing more insurance. ${ }^{14}$ The total value of property insured under the NFIP was US $\$ 165$ billion in 1978, US\$348 billion in 1990, and US\$703 billion in 2000. Between 2001 and 2010, the total exposure increased by another 75 per cent, reaching US\$1.23 trillion at the end of December 2009 (corrected for inflation; 2009 prices). This level has remained stable since. On 1 January 2014, there were 5.47 million NFIP policies in force nationwide which generated US\$3.53 billion in premiums (average annual premium per policy of US\$645 nationwide) for a total of US\$1.28 trillion under coverage. Highly populated coastal states have the largest number of flood insurance policies in the NFIP, as would be expected. In particular, two states-Florida and Texas-represent more than 50 per cent of the entire NFIP policies in force; approximately 70 per cent of all policies are in five states-Florida, Texas, Louisiana, California, and New Jersey. ${ }^{15}$

\section{Limits of the current NFIP flood insurance premium pricing approach ${ }^{16}$}

The NFIP's goals with regard to setting prices differ from those of a private insurance company for several reasons. The NFIP does not have to make a profit nor must its premiums reflect the cost of capital insurers would have to pay. It also does not have to be concerned with the risk of insolvency due to truly extreme events since it can borrow ex post from the U.S. Treasury to meet its claims. ${ }^{17}$ Furthermore, approximately 25 per cent of all policies are subsidised, while the remaining properties are charged the average historical loss-based rates as determined by FEMA.

To set premiums and support local governments, the NFIP maps participating communities, designating flood risks through different flood zones. These maps are called Flood Insurance Rate Maps (FIRMs). A building that was in place pre-FIRM-before the mapping of flood risk was completed in that area-is often given subsidised rates. Homes built after the risk mapping are charged premiums reflecting FEMA's flood maps. The programme was structured to subsidise the cost of flood insurance on existing homes, in order to maintain property values, while charging actuarially fair rates on new construction. There was an expectation that fewer policies would be subsidised over time. However, around a quarter of properties are still subsidised today since the housing stock is turning over more slowly than predicted, partly because of new renovation techniques that have extended the life of buildings. ${ }^{18,19}$

The goal of the programme-wide pricing strategy is to collect enough premiums to cover the operating expenses and losses associated with the historic average loss year without accounting for the possibility of a truly catastrophic event. ${ }^{20}$ Premiums set by FEMA are determined first using the NFIP's Actuarial Rate Formula described in their annual rate reviews. This pricing is focused on the high-risk A and V flood zones. The high-risk A zones

\footnotetext{
${ }^{14}$ Inflation-corrected data shows that the average quantity of insurance per policy almost doubled over 30 years, from US\$114,000 in 1978 to US\$217,000 in 2009 (Michel-Kerjan, 2010).

15 All states have at least some NFIP policies in force. The states with the lowest number of policies in force - all less than 5,000 policies are: Alaska, the District of Columbia, Montana, North Dakota, South Dakota, Utah, Vermont and Wyoming.

${ }^{16}$ We thank the NFIP team of actuaries at FEMA for their feedback on an earlier version of this section.

${ }^{17}$ Hayes et al. (2007).

18 Pasterick (1998); Wetmore et al. (2006); CBO (2007); Kousky (2011).

${ }^{19}$ See Bin and Polasky (2004) and Bin et al. (2008) for an analysis of how flood hazard negatively impacts housing market price.

${ }^{20}$ Hayes and Spafford (2008).
} 
are defined as areas with a 1 per cent or greater annual chance of flooding; V zones are defined as coastal areas with a 1 per cent or greater annual chance of flooding and an additional hazard associated with storm waves. A definition of FEMA flood zones is provided in Appendix A.

The problem is that flood magnitude is not limited to what would be deemed a 100-year flood depth amount. The return period of the storm tracks for Hurricane Sandy has been estimated at about 700 years, ${ }^{21}$ and storm surge depth was in the 1,000-year return period range. $^{22}$ Very low probability disasters do occur; it is thus important to integrate these events into the pricing mechanism. Since the NFIP was designed to be able to compensate the average flood event and could tap into the U.S. Treasury to borrow money in case a truly catastrophic event happened, its pricing mechanism does not necessarily take into account the consequences of such extreme events. Private insurers normally consider the entire spectrum of events because they are responsible for paying all the legitimate claims covered in the policy. The catastrophe model used in this paper determines house-based flood exposure by including flood events ranging from an annual likelihood of 1 in 100 to extremely low probabilities that include events whose annual probability of occurrence is as low as 1 in 10,000.

FEMA rates also vary depending on the elevation of the first floor of the dwelling in relation to the 100-year return flood event; however, FEMA does not collect elevation information for many of the insured houses. Since one specific flood zone typically covers a fairly large area, local topological differences are not taken into account when setting FEMA premiums. Rates for other zones outside of the 100-year flood plain, such as X zones, are derived from a general national model rather than local flood risk maps.

This overall pricing strategy thus leads to important divergences from the true risk for a number of residents covered by the programme. Rates are not risk-based at the individual level (probabilistically defined), so prices might be (way) "too high" in some areas and (way) "too low" in others, even if some of these properties were supposedly given a subsidy. The U.S. Government Accountability Office (GAO) recognised this as a problem several years ago $^{6}$ but to date there has not been any quantification of this divergence in the published literature because, until recently, the data was maintained within FEMA and the technology was not capable of pricing flood risk at a granular level.

These discrepancies between NFIP's pricing versus probabilistic risk estimates that integrates the local characteristics of the property have had important consequences on the financial balance of the programme. Claims from Hurricanes Katrina, Rita and Wilma and other floods in 2005 pushed the operating budget of the programme into debt. Hurricane Katrina alone generated US\$16.1 billion in flood insurance payments. Between 2005 and 2008 (due to claims from Hurricane Ike in Texas in 2008), the programme had to borrow a total of US\$19.3 billion from the U.S. Treasury. ${ }^{23}$ The NFIP had started to repay some of these funds until it was hit by Sandy-related floods in 2012; it currently incurs a US\$27 billion deficit.

It will be very difficult for the programme to repay this debt: total annual premiums for the programme are about US\$3.5 billion and annual interest payments alone have been as

\footnotetext{
${ }^{21}$ Hall and Sobel (2013).

22 Aerts et al. (2014).

23 King (2012).
} 
high as US\$900 million. In some sense, the debt accumulated after the 2005 and 2008 losses just confirmed what was known since the inception of the programme: it was designed to be financially self-supporting, or close to it, most of the time, but cannot handle extreme financial catastrophes by itself. ${ }^{24,25}$

\section{Determination of flood insurance pure premiums using catastrophe modelling}

This section undertakes a detailed analysis of how much risk-based pure premiums should be at the single-family residence level in two Texas counties when incorporating extreme flood events.

\section{Focus on Texas}

Texas is a natural candidate for this pilot study for several reasons. The state is exposed to both storm surge-related flooding and to riverine flooding. It is the second most populous state in the U.S. after California with over 24 million residents, approximately one-third of them residing in a coastal county. Texas is one of the fastest growing states in the nation, averaging 21 per cent population growth per decade since 1960 compared to an average 11.4 per cent population growth per decade for the entire United States over the same time period. It has the second largest state gross domestic product (GDP) in the U.S. at over US\$1.2 trillion dollars ${ }^{26}$ ). Today it has 12 per cent of the total NFIP policies in force.

An analysis of NFIP claims reveals that the majority of Hurricane Ike's US\$2.6 billion in flood insurance claims were filed by policyholders in a number of Texas counties. We focus the study on two specific counties, Travis (inland county; riverine flood), which includes the capital city of Austin, and Galveston (coastal county along the Gulf of Mexico; riverine and storm surge flood) (Figure 1). Together they total 1.3 million residents. ${ }^{27}$ These two counties are among the top seven most flooded counties of the total 254 in Texas over the period 1960-2009, with Galveston being fifth and Travis seventh. ${ }^{28}$ Galveston is also the Texas county most frequently hit by hurricanes and tropical storms over this time period.

\section{Determination of risk-based pure premiums using catastrophe models}

In order to determine the risk-based pure premiums that should be charged to cover the flood risk, estimates must be made of the frequency of specific events and the likely extent of resulting losses. Traditional statistical techniques used by actuaries for estimating future losses that rely on a wealth of available claims data, for example such as from automobile accidents or house fires. They are not appropriate for estimating future losses from natural catastrophes because of the relatively low frequency of these events. A probabilistic approach to catastrophe loss analysis, that is, catastrophe modelling, is the most appropriate

\footnotetext{
${ }^{24}$ Wetmore et al. (2006).

25 Note that we have focused here on the insurance pillar of the NFIP; the programme also integrates several other elements (e.g. risk mapping; Community Rating System; risk awareness campaigns).

${ }^{26}$ U.S. Bureau of the Census (2011).

27 Texas State Data Center (2011).

${ }^{28}$ SHELDUS (2011).
} 


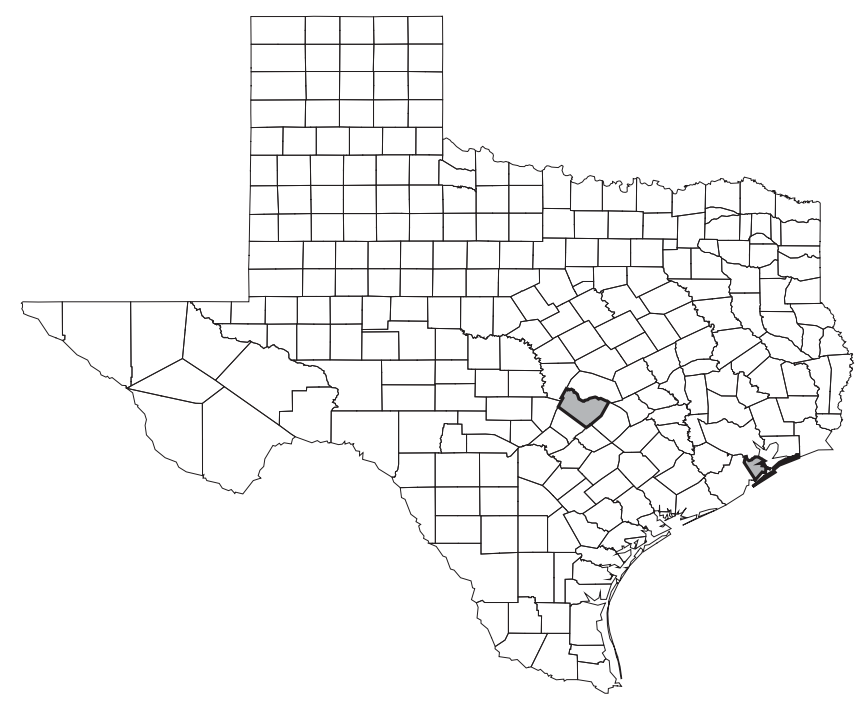

Figure 1. Focus of the study: Counties of Galveston (coastal) and Travis (inland), TX.

way to handle these loss data challenges. The catastrophe model used for this analysis was jointly provided by CoreLogic (one of the largest data providers in the United States) and the reinsurance company Swiss Re. ${ }^{29}$

The proprietary nature of the model precludes us from revealing its details but we provide its features below. Furthermore, while Corelogic is a commercial firm it is a primary source of data for the U.S. federal government. ${ }^{30}$ The SwissRe flood model has been used by a number of clients around the world, ${ }^{31}$ including several public entities in the United States. For instance, New York City used the Swiss Re model to assess its exposure and undertake benefit/cost analyses of several risk reduction measures in the aftermath of Hurricane Sandy. 1,32 We feel the use of these models by public sector organisations provides a level of assurance regarding its validity. More details on this point are provided in Appendix B.

A probabilistic catastrophe modelling approach provides more value than a deterministic approach because it includes all the expected events that can cause damage and it generates a detailed analysis of return periods based on advanced hazard models. The four basic modules of a catastrophe model are: hazard, inventory, vulnerability and loss. ${ }^{33}$

29 The flood model originally built by Swiss Re is executed by CoreLogic with hazard, exposure and vulnerability components jointly enhanced from each organisation building on each of their respective data strengths.

${ }^{30}$ The CoreLogic database consists of over 3.3 billion property and financial records spanning 40 years, and contains more than 99 per cent of U.S. property records. Nineteen federal agencies rely on CoreLogic data for their analyses.

31 www.media.swissre.com/documents/pitchbook_global_flzones_final.pdf(accessed 1 September 2014)

${ }^{32}$ In Europe, a group of insurance companies has been working with the European Space Agency on a project to improve flood risk quantification. The joint effort between satellite operators, Earth observation service providers and the insurance industry will provide detailed flood footprints based on satellite data.

${ }^{33}$ For more information on catastrophe modelling, see Grossi and Kunreuther (2005) and Born and Martin (2006). 
The hazard module includes two main parts. ${ }^{34}$ The first part addresses the occurrence and frequency of the events. It does this by first developing a stochastic event set, a set of simulated events characterising the observed or scientifically modelled events and their probabilities of occurrence. The second part of the hazard module calculates the severity of the events at every site of the study region.

Flood hazards within the CoreLogic and Swiss Re models are comprised of both riverine flooding and hurricane-related storm-surge flooding for coastal locations. The riverine flood inundation water depths from a collection of flood events at a given property's latitude and longitude are computed through an empirical relationship determined by the probability of flood occurrence combined with the flood intensity of the events. By specifying the set of water depths across all flooded properties, one can then determine the financial loss impacts of flood events on a targeted geographical area. The CoreLogic and Swiss Re models generated 400,000 simulated riverine flood events in the United States; specific to our analysis, approximately 2,000 of them impacted Galveston County and approximately 5,000 of them impacted Travis County (see Appendix B for more information).

The hurricane storm-surge flood inundation water depths for a given coastal location are computed through an empirical relationship determined by the storm surge heights (associated with hurricanes of different intensities) at different landfall locations, combined with the stochastic hurricane event set defining storm surge location, frequency and intensity. Thus, the resulting storm-surge flood event is defined as the set of varying water depths across all flooded properties within the predetermined coastal geographical area. The probabilistic flood event set generated in the storm surge module provides simulated data for tropical cyclones over 10,000 years based upon statistical data for storms in the North Atlantic and Gulf Coast regions over the past 150 years. Over 100,000 individual storm tracks are represented and approximately 1,000 of them impacted Galveston County. A coastal model was used to determine the geospatial distribution of storm surge heights generated from the five different hurricane intensity categories striking the U.S. coast. The storm surge module utilises maximum storm surge heights to simulate the resulting surge impact area and corresponding water depths (see Appendix B for more information).

The second module of a catastrophe model characterises the inventory of the properties at risk. This can be a building of specific interest, a dwelling representative of the average construction type in a given area exposed to the hazard, or an entire portfolio of buildings with different characteristics (e.g. an entire city).

Here we focused on single-family residences at risk from flooding. Data on elevation and flood zone for 226,407 single-family residences were collected by CoreLogic and input into the CoreLogic and Swiss Re flood catastrophe model for Travis County. These 226,407 single-family residences represent 76 per cent of the 316,479 parcels collected by CoreLogic for Travis County. (The next largest group of parcels in each county is vacant property, which is land only and therefore would have no property exposed to floods; see Appendix B for more detail on the inventory).

We then overlap the GIS-based information on residences with the FEMA flood insurance rate maps for these areas in Texas. Table 1 provides the total number of singlefamily residences located in different FEMA flood zones as well as the mean exposure

\footnotetext{
${ }^{34}$ For more information about the flood catastrophe model used here, see Czajkowski et al. (2013).
} 
The Geneva Papers on Risk and Insurance-Issues and Practice 10

Table 1 Travis County exposure value summary by FEMA flood zone

\begin{tabular}{lccccc}
\hline FEMA flood zone & $\begin{array}{c}\text { Number of single-family } \\
\text { residences }\end{array}$ & $\begin{array}{c}\text { \% of total } \\
\text { residences }\end{array}$ & $\begin{array}{c}\text { Total exposure } \\
\text { value }\end{array}$ & $\begin{array}{c}\text { \% of total } \\
\text { exposure value }\end{array}$ & $\begin{array}{c}\text { Average } \\
\text { exposure value }\end{array}$ \\
\hline A & 6,790 & 3 & $\$ 1,536,512,177$ & 3 & $\$ 226,290$ \\
X500/B & 5,010 & 2 & $\$ 1,125,747,322$ & 2 & $\$ 224,700$ \\
X/C & 214,607 & 95 & $\$ 51,806,029,170$ & 95 & $\$ 241,400$ \\
Total county & 226,407 & 100 & $\$ 54,468,288,669$ & 100 & $\$ 240,577$ \\
\hline
\end{tabular}

${ }^{\mathrm{a}}$ Exposure value $=$ Building value +40 per cent contents.

values input into the model in each zone used for this analysis. ${ }^{35}$ In our data sample, Travis County has over US\$54 billion in exposure with 95 per cent of this exposure in the designated low-risk X/C FEMA flood zone, which is outside of the 100- and 500-year-return flood plains.

The third module quantifies vulnerability, that is, how these properties at risk (inventory) will behave physically under events that the hazard module has generated. Vulnerability functions are the relationships between hazard intensity (e.g. water depth) and the level of damage experienced. Vulnerability for each flood hazard in the catastrophe model is the average proportion of the property damaged (mean damage ratio) as a function of the specified flood depth determined by generating a large number of possible flood scenarios. The combination of exposure and vulnerability is obtained by gauging the flood inundation depth at each specific location due to riverine or storm-surge flooding from any of the probabilistic events. (Appendix B).

The fourth module is loss. It is determined by taking total value of damage given the inventory exposure value and calculating the total loss based on engineering studies for specific type of construction, elevation, location, etc. They can also be calibrated with insurance claims data.

These losses are then compiled and collected in a table called an event loss table (ELT). A typical ELT is such that each row corresponds to a catastrophe event taken from a group of credible scenarios (e.g. flood) with an identification number (Event ID $j$ ), an annual rate of occurrence $(\lambda j)$ and resulting loss $(L j)$ for IDj (Table 2).

Combining information on frequency and severity of losses, the probabilistic catastrophe model generates the distribution of the expected losses associated with all possible scenarios of disasters (here, floods). This is often expressed in terms of an aggregate loss exceedance probability (EP) curve. For a given house or portfolio of structures at risk, an EP curve is a graphical representation of the probability $p$ that a certain level of aggregated loss $\$ L$ will be exceeded in a given year. The Average Annual Loss (AAL), which represents the expected loss over all simulated events for an individual home in a given year, equals the area under the EP curve.

\footnotetext{
${ }^{35}$ The total insured value of these single-family residences input into the model was the collected building value with a conservatively assigned content assumption of 40 per cent of the building value which is aligned with Swiss Re client data content percentages. Building value was provided by CoreLogic as the market improvement value, where market improvement value equals the residence's total market value net of the market land value with all market values as provided by the county or local taxing/assessment authority.
} 
Table 2 Example of an event loss table

\begin{tabular}{lcc}
\hline Event ID & Annual rate of occurrence & Loss \\
\hline 1 & $\lambda_{1}$ & $L_{1}$ \\
2 & $\lambda_{2}$ & $L_{2}$ \\
$\ldots$ & $\cdots$ & $\cdots$ \\
$k$ & $\lambda_{k}$ & $L_{k}$ \\
$\ldots$ & $\cdots$ & $\ldots$ \\
$K$ & $\lambda_{K}$ & $L_{K}$ \\
\hline
\end{tabular}

To account for the impact of the exposure value on the derived AAL, the ratio of AAL over quantity of exposure per US $\$ 1,000$ is also determined. This is the pure premium.

The total loss from a single event is then the aggregate of losses in all sites of the study region due to that event. With AAL values of individual residences it is indeed possible to sum such estimates for all single-family residences in a given county or in a given FEMA flood zone for that county.

\section{Results for Travis County}

Table 3 presents AAL results for Travis County from the analysis we just described, grouped by FEMA flood zone where the properties are located. The column labelled "peril" reveals that all single-family residences in the A (high risk) and X500 (moderate risk) zones have some level of flood risk loss associated with them as an outcome of our catastrophe model. Total AAL in the A and X500 zones is US\$10.2 and US\$2.3 million respectively. ${ }^{36}$ Although 77 per cent of the single-family residences in this low-risk $\mathrm{X}$ zone have no riverine flood risk associated with them, there are still nearly 50,000 single-family residences with some flood risk having a total AAL $=$ US $\$ 3.9$ million from their associated total US $\$ 9.3$ billion in exposure. This provides an example of a relatively significant amount of flood risk associated with a FEMA-designated "minimal" flood risk zone from a catastrophe model perspective.

On average, total AAL per single-family residence is over three times higher in the A zone (US\$1,508) compared with the X500 zone (US\$461), and over 18 times higher than the 49,069 at-risk single-family residences in the X zone (US\$81). Similarly, when accounting for differences in the exposure value across zones, the US\$5.51 mean AAL cost per US $\$ 1,000$ in the A zone is still approximately 3 and 18 times higher than the US\$1.69 and US $\$ 0.31$ mean AAL cost per US $\$ 1,000$ for the X500 and X zones, respectively. ${ }^{37}$

Despite this decline in high to low risk when moving from A to X500 to X zones as represented by the high to low mean total AAL and loss costs per US\$1,000 respectively, the

\footnotetext{
${ }^{36}$ In Travis County, total AAL is comprised of only riverine flood loss as Travis County is an inland county not subject to storm surge losses. Total AAL in Galveston County is comprised of both riverine and storm surge flood losses.

${ }^{37}$ Note that these values are the average across each individual single-family residence's AAL exposure per US $\$ 1,000$ determined result. Consequently, taking the (Total AAL/Total Exposure) times 1,000 at the county or flood zone levels shown in Table 2 will not provide the same result. We find that the median is US\$3.44, US\$0.34 and US\$0.08 for single-family residences in zones A, X500 and X/C, respectively (the skewness is $0.55,2.24$ and 8.35 , respectively).
} 
The Geneva Papers on Risk and Insurance-Issues and Practice

12

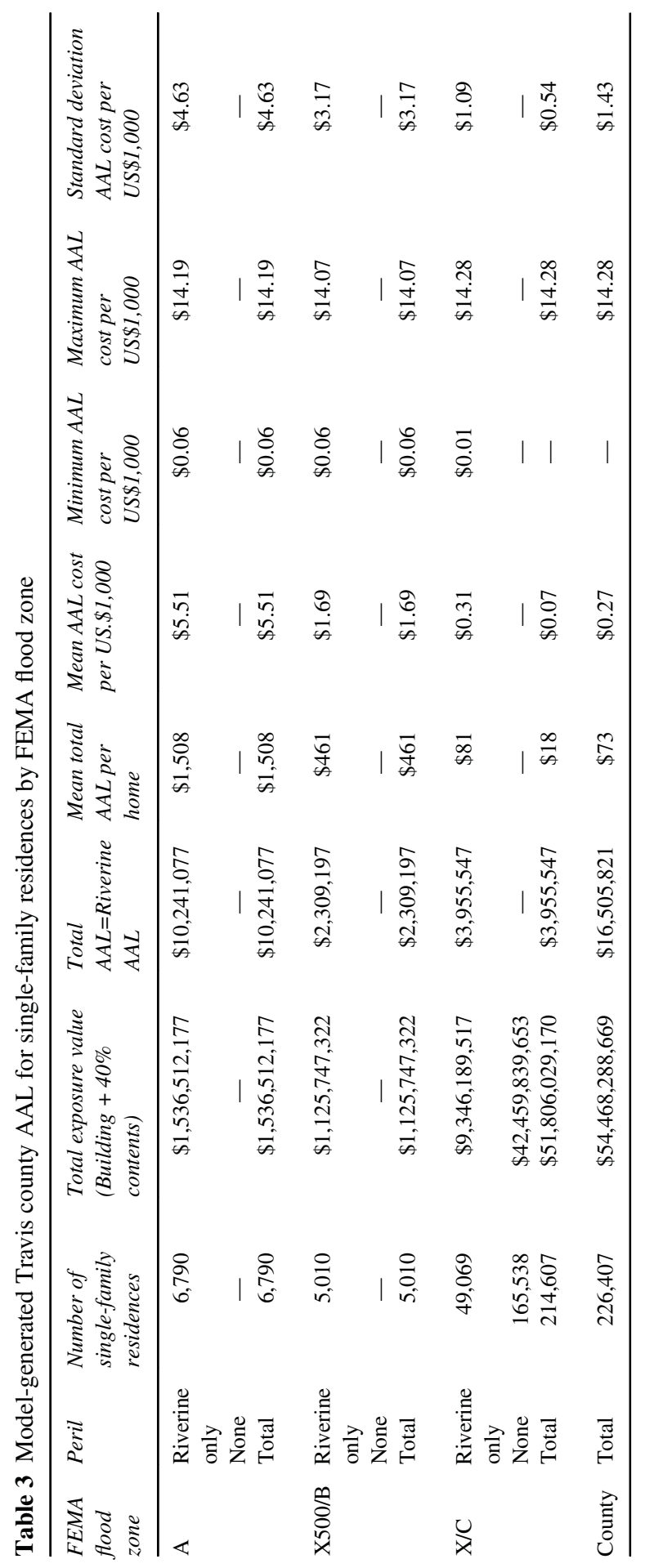


range of AAL costs per US $\$ 1,000$ across all three flood zones is essentially the same, ranging from US $\$ 0.06$ per US $\$ 1,000$ of exposure to US $\$ 14$ per US $\$ 1,000$ of exposure. This would indicate that some residences that are considered high risk by FEMA (because they are located in an A zone) might actually be low risk due to their specific location within that zone and/or special characteristic of the house. On the other hand, some residences located in a FEMA designated low-risk zone can actually be highly exposed to flooding. In fact, the highest AAL cost per US $\$ 1,000$ of exposure is US $\$ 14.28$ located in the Travis County $\mathrm{X}$ zone, which is outside of the designated high and moderate risk FEMA flood zones. Thus, if one only considers the average flood risk in a given FEMA zone, the heterogeneity of risk across properties is not taken into account.

Our results for Travis County highlight the importance of undertaking a microanalysis of the exposure of residents to riverine flood and storm surge to determine the risk-based pure premium associated with a given single-family residence. Similarly classified FEMA flood zones in different parts of the country can have significantly different flood risks and hence different risk-based pure premiums. Thus, one cannot simply average the risk in a given flood zone to specify premiums. Using the results of this AAL analysis for Travis County as well as a similar analysis for Galveston (below), we can compare premiums computed by the catastrophe model with those currently charged by NFIP to residents in these two counties. We now turn to this comparison.

\section{Comparison of our catastrophe-model results with NFIP premiums}

\section{Unloaded premium comparison}

Insurance premiums charged to consumers are comprised of risk-based AAL and other loading factors such as administrative expenses, cost of capital, etc. In the previous section we calculated the unloaded risk-based pure premium that is, the average annual loss accounting for all possible events considered by the catastrophe model without any loading cost. To compare this unloaded premium with a similar unloaded NFIP premium, administrative expenses from the NFIP premium rates must be subtracted. Let $\lambda$ be the loading cost charged by the NFIP. Hence the NFIP premium for a residential structure is $(1+\lambda) A A L$, where $A A L$ was calculated by FEMA. In an analysis of the financial operation of the first 40 years of the programme, Michel-Kerjan ${ }^{2}$ finds that the average value of $\lambda_{N F I P}$ is about 50 per cent. This pays for programme expenses such as fees to participating insurers and agents selling flood insurance policies and assessing claims on behalf of the NFIP, operating costs of the programme and flood risk mapping.

We accessed the entire portfolio of the programme for the two counties under study for the year 2009 and generated the implicit AAL by subtracting this loading cost from the full premiums charged by the NFIP to obtain the adjusted average loss cost. ${ }^{38}$ Table 4 presents the results of our unloaded premium comparison for 226,407 single-family residences in Travis

\footnotetext{
38 The NFIP data set we accessed from FEMA provides us only with ZIP codes which we used to extract associated NFIP single-family policy data for Travis County and Galveston County. We used 60 ZIP codes for Travis County and 17 ZIP codes for Galveston County. We also conducted a series of robustness checks on this matched ZIP code data with very similar results as to what is presented here.
} 
County from Table 3 and our generated unloaded NFIP premiums for 7,723 residences with NFIP policies in that county. ${ }^{39}$ Note that because of low insurance penetration, the number of NFIP policies in force is typically much lower than the number of single-family residences.

A key result shown in the Table 4 comparison is that the mean probabilistically based pure premium, AAL (as an outcome of our catastrophe model) is sometimes higher and sometimes lower than the comparable adjusted average premium currently charged by the NFIP. For example, the average adjusted NFIP average loss cost for the X500 zone (areas of moderate flood hazard) is US $\$ 3.19$ per US $\$ 1,000$ of coverage, almost two times higher than the US $\$ 1.69$ per US $\$ 1,000$ of exposure from our probabilistic model. In the X zone (areas of minimal flood hazard) the difference is much larger: US\$1.13 vs US\$0.07-on average the NFIP overcharges by a factor of 16 in that zone. ${ }^{40}$

However, in the Travis County A zone (high-risk 100-year flood zone) we see that the model shows a mean pure premium of US\$5.51 per US\$1,000 of coverage, roughly 1.5 times larger than the comparable average adjusted NFIP premium of US\$3.47.

In other words, in Travis County, on average, the NFIP overcharges insured residents in low-risk areas and undercharges those in high-risk areas. ${ }^{41}$ But even in cases when the pure premium would on average be higher than what is currently charged by FEMA (e.g. A zone in Travis County; US\$5.51 vs US\$3.47; see Table 4), the result from the catastrophe model analysis is not necessarily true for all residences, contrary to what one often hears about the NFIP always undercharging high-risks, as illustrated in Figure 2, which depicts the distribution of our two samples for different premium brackets.

In fact, 50 per cent of the 6,790 A zone residences' unloaded premiums from our study fall below the average NFIP A zone pure premium amount of US\$3.47. Similarly, 84.1 per cent of the 5,010 X500 zone policies from the model have an unloaded premium less than the average X500 NFIP pure premium of US\$3.19, ${ }^{42}$ and 99.2 per cent of the $214,607 \mathrm{X}$ zone policies from the model have an unloaded premium less than the average $\mathrm{X}$ zone NFIP pure premium of US\$1.13 (figures not reported in the tables).

Taken together, these findings show that conventional wisdom about the NFIP is incorrect. Indeed, it has been said that the NFIP systematically overprices low risk and underprices high risks. ${ }^{43}$ But we also find that some high-risk properties are actually overpriced and some low-risk properties are underpriced. Thus, there is likely to be a significant opportunity for the insurance industry to market insurance at lower rates than the NFIP, especially in lowrisk areas, if insurers are allowed to charge risk-based premiums.

Let us reiterate here several possible reasons for these findings. Many FEMA flood maps are outdated (due mainly to limited resources at their disposal). Advanced flood mapping technologies employed by private firms are able to address the existing FEMA flood map limitations. For instance, the overall extent of the flood zones is expanded to outside the

\footnotetext{
${ }^{39}$ We also conducted a similar analysis for the 188,496 single-family residences in Travis County with a building value less than or equal to the NFIP building value coverage limit of US\$250,000 (83 per cent of total singlefamily residences analyzed). Average loss cost results per US $\$ 1,000$ were very similar.

${ }^{40}$ This X zone result also holds for the 49,069 single-family residences in the X zone that have some flood exposure: the average probabilistic pure premium in this case is US\$0.31 as shown in Table 2.

41 Travis County's location is such that there is no storm surge risk there; so no $\mathrm{V}$ zone.

${ }^{42}$ Note here that this is based on only 48 policies; so results may not be representative.

43 King (2012); PCIAA (2011)
} 
Erwann Michel-Kerjan, Jeffrey Czajkowski and Howard Kunreuther Could Flood Insurance be Privatised in the United States?

Table 4 Travis County unloaded premium comparison: Unloaded probabilistic flood model and unloaded NFIP pure premiums

\begin{tabular}{|c|c|c|c|c|c|c|}
\hline \multirow{2}{*}{$\begin{array}{l}\text { FEMA } \\
\text { flood zone }\end{array}$} & \multicolumn{3}{|c|}{ Travis County study AAL results } & \multicolumn{3}{|c|}{ NFIP unloaded premium data } \\
\hline & $\begin{array}{l}\text { Number of } \\
\text { single-family } \\
\text { residences }\end{array}$ & $\begin{array}{c}\text { Mean total } \\
\text { AAL per } \\
\text { home }\end{array}$ & $\begin{array}{c}\text { Mean AAL } \\
\text { cost per } \\
\text { US\$1,000 }\end{array}$ & $\begin{array}{l}\text { Number of } \\
\text { single-family } \\
\text { residences }\end{array}$ & $\begin{array}{c}\text { Adjusted }(67 \%) \\
\text { average NFIP } \\
\text { premium }\end{array}$ & $\begin{array}{c}\text { Adjusted } \\
\text { average } \\
\text { loss cost per } \\
\text { US\$1,000 }\end{array}$ \\
\hline A & 6,790 & $\$ 1,508$ & $\$ 5.51$ & 3,726 & $\$ 512$ & $\$ 3.47$ \\
\hline X500/B & 5,010 & $\$ 461$ & $\$ 1.69$ & 48 & $\$ 462$ & $\$ 3.19$ \\
\hline $\mathrm{X} / \mathrm{C}$ & 214,607 & $\$ 18$ & $\$ 0.07$ & 3,949 & $\$ 239$ & $\$ 1.13$ \\
\hline $\begin{array}{l}\text { Travis County } \\
\text { total }\end{array}$ & 226,407 & $\$ 73$ & $\$ 0.27$ & 7,723 & $\$ 372$ & $\$ 2.30$ \\
\hline
\end{tabular}

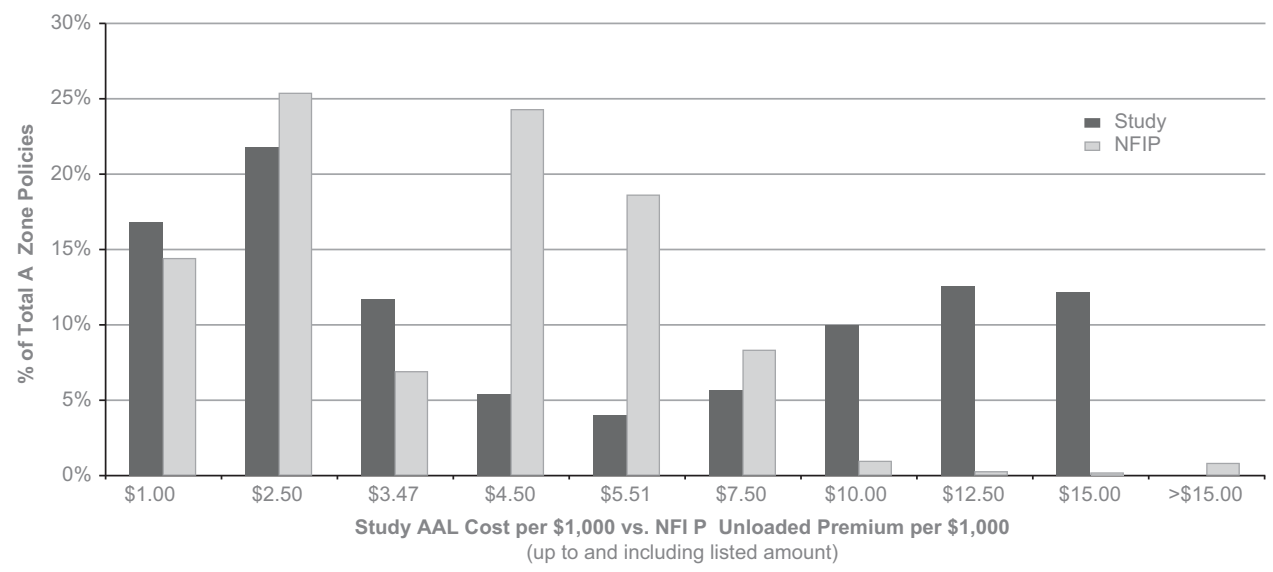

Figure 2. Distribution of AAL vs NFIP unloaded pure premiums.

FEMA 100-year and 500-year flood zone boundaries through a flood elevation variancebased methodology and intrinsic characteristics of the riverine system. In addition, these features are continuously revised through live flood map updates and therefore, the hazard module is also continuously revised with approximately 1,000 modifications per year incorporated into the hazard module.

Furthermore, a catastrophe model probabilistic approach includes 200-year, 500-year, 1,000-year and greater flood magnitudes, whereas FEMA rates do not include those very low probability events in the tail of the distribution. In other words, FEMA truncates the tail of the distribution, whereas a catastrophe model integrates the possibility of truly catastrophic losses into the flood assessment (e.g. events with a 500-year, 1,000-, 5,000-year return period). Significant flood events are not limited to the 100-year floodplain and could affect structures in FEMA-designated minimal flood risk areas. 
Also, while the NFIP calculates rates for a variety of floodplains within the high-risk A and $\mathrm{V}$ zones, the final elevation-based rates are set for each flood zone for the nation as a whole; rates for structures with the same elevation difference in similar flood zones are the same everywhere in the country. As such some residences that are considered high risk by FEMA (because they are located in an A zone) might actually be low risks because of a specific location within that zone and/or special characteristic of the property, such as its elevation. Rates for other zones outside the high-risk areas, such as the moderate risk X500 and minimal risk $\mathrm{X}$ zones, are derived from the high-risk modelled rates rather than their own distinct local flood risk maps. This pricing strategy clearly leads to important crosssubsidisations in the programme. Rates are not risk-based at the local level (probabilistically defined), so prices will be "too high" in some areas and "too low" in others, as our results in Table 4 show.

We undertook a similar analysis (comparing the AAL derived from the catastrophe model with the NFIP unloaded premiums) for all single-family residences located in Galveston County, which is prone to both riverine flood and storm surge (hence we introduce the coastal high-risk $\mathrm{V}$ zone in our analysis). Table 5 presents the results of this comparison. For Galveston, the model results are based upon 89,046 residences while there are 68,644 residences in the comparable NFIP data set for the 17 matched Galveston County ZIP codes. This difference is greatest in the X500 zone with the 5,988 NFIP policies collected representing 31.6 per cent of the single-family residences in Galveston County within the X500 zone from our model. The large number of NFIP X zone policies in Galveston (93 per cent of the 46,829 model policies) indicate that there is significant risk in this $\mathrm{X}$ zone despite its classification of minimal risk.

The unloaded premiums across flood zones is not systematically higher than the comparable average premium being charged by the NFIP. The results in Table 5 show that on average the NFIP undercharges residents in A zone in Galveston County (US $\$ 3.43$ vs US\$6.61 according to the catastrophe model) as it does for those in A zone in Travis County (US\$3.47 versus US\$5.51). ${ }^{44}$ We find that 12.1 per cent of the $17,940 \mathrm{~A}$ zone policies from the model have an unloaded premium less than the average NFIP A zone pure premium of US\$3.43. However, while it on average overcharges residents in moderate and minimal risk zones (X500 and X) in Travis County, on average it undercharges residents in similar flood zones in Galveston County (US\$1.29 vs US $\$ 4.21$ in X500 zones; US $\$ 0.96$ vs US\$1.64 in $\mathrm{X}$ zones). Overall, 2.6 per cent of the 18,922 X500 zone model policies and 34.5 per cent of the $46,829 \mathrm{X}$ zone model policies are below the respective US $\$ 1.29$ and US $\$ 0.96$ NFIP $\mathrm{X} 500$ and $\mathrm{X}$ zone average unloaded premiums. Again, we find important elements of crosssubsidisation within each of the risk categories where some high-risk properties are actually over-priced and some low-risk properties are underpriced.

Turning to storm surge risk, the adjusted average NFIP pure premium for the Galveston County V zone is US $\$ 9.49$ per US $\$ 1,000$ of coverage, compared with US\$6.60 per US $\$ 1,000$ from our model. ${ }^{45}$ Indeed, 90.1 per cent of the 5,355 V zone unloaded premiums

\footnotetext{
${ }^{44}$ Dixon et al. (2007) found a similar result for the lender-place market only-see Table 4.2, p. 32.

45 Storm surge flood-related losses are the main driver behind the Table 4 probabilistic model unloaded premium results comprising at least 89 per cent of the average AAL loss costs per US $\$ 1,000$ values across all flood zones even for the areas outside the high-risk V and coastal A zones, or the areas not subject to storm-surge flood risk according to FEMA flood zone classifications.
} 
Erwann Michel-Kerjan, Jeffrey Czajkowski and Howard Kunreuther Could Flood Insurance be Privatised in the United States?

Table 5 Galveston County premium comparison: Unloaded probabilistic flood model and unloaded NFIP pure premiums

\begin{tabular}{|c|c|c|c|c|c|c|}
\hline \multirow{2}{*}{$\begin{array}{l}\text { FEMA } \\
\text { flood zone }\end{array}$} & \multicolumn{3}{|c|}{ Galveston County study AAL results } & \multicolumn{3}{|c|}{ NFIP unloaded premium data } \\
\hline & $\begin{array}{l}\text { Number of } \\
\text { single-family } \\
\text { residences }\end{array}$ & $\begin{array}{c}\text { Mean total } \\
\text { AAL per } \\
\text { home }\end{array}$ & $\begin{array}{c}\text { Mean } A A L \\
\text { cost per } \\
U S \$ 1,000\end{array}$ & $\begin{array}{l}\text { Number of } \\
\text { single-family } \\
\text { residences }\end{array}$ & $\begin{array}{c}\text { Adjusted }(67 \%) \\
\text { average NFIP } \\
\text { premium }\end{array}$ & $\begin{array}{c}\text { Adjusted average } \\
\text { loss cost per } \\
U S \$ 1,000\end{array}$ \\
\hline $\mathrm{V}$ & 5,355 & $\$ 1,776$ & $\$ 6.60$ & 2,938 & $\$ 2,224$ & $\$ 9.49$ \\
\hline A & 17,940 & $\$ 969$ & $\$ 6.31$ & 16,286 & $\$ 534$ & $\$ 3.43$ \\
\hline X500/B & 18,922 & $\$ 485$ & $\$ 4.21$ & 5,988 & $\$ 215$ & $\$ 1.29$ \\
\hline $\mathrm{X} / \mathrm{C}$ & 46,829 & $\$ 251$ & $\$ 1.64$ & 43,432 & $\$ 217$ & $\$ 0.96$ \\
\hline $\begin{array}{l}\text { Galveston } \\
\text { County total }\end{array}$ & 89,046 & $\$ 537$ & $\$ 3.43$ & 68,644 & $\$ 378$ & $\$ 1.94$ \\
\hline
\end{tabular}

from our study fall below the average NFIP unloaded premium amount of US\$9.49. Clearly, the conventional wisdom that the NFIP systematically underprices high-risk properties is shown not to be true in these two counties.

On the other hand, many residences are not classified by FEMA as being in a $\mathrm{V}$ zone even though they should be, as illustrated by Hurricane Ike in 2008, which was primarily a storm-surge flooding event. Our analysis of the NFIP portfolio reveals that there were nearly 20,000 NFIP claims in Galveston County from Hurricane Ike, totalling US $\$ 1.3$ billion in insured losses. But we find that only approximately 3,000 (15 per cent) of Galveston's claims from Ike could have been from the Galveston County's V zone given the number of policies in force there. Consequently, it is likely that 85 per cent of the total Ike claims were from policies that on average are being charged premiums less than the risk-based premiums as shown in Table 5 for A, X500, and X zones (US\$3.43 vs US\$6.61, US $\$ 1.29$ vs US $\$ 4.21$, and US $\$ 0.96$ vs US $\$ 1.64$, respectively). It is doubtful that underpricing 85 per cent of total policies is a viable long-term financial position, even if another 15 per cent of policies are overpriced on average.

\section{Full (loaded) premium comparison}

The NFIP's goals with respect to setting prices differ from those of a private insurance company because the NFIP does not have to seek a profit, nor must its prices reflect the cost of capital that private insurers need to set aside to meet solvency requirement from regulators and rating agencies. Paying federal/foreign income taxes and premium taxes is another requirement that private insurers must bear. Here we are interested in comparing the full premiums charged by the NFIP to what private insurers would have to charge given their own constraints should they want to offer the same coverage to single-family residences living in these two counties; that is the loaded premium.

In order to compare this full premium to the NFIP premiums, a private sector firm's loading factor must be added to the modelled pure premium values from Tables 4 and 5 . 
The Geneva Papers on Risk and Insurance-Issues and Practice

18

Table 6 Travis County full premium comparison: NFIP and probabilistic flood model with various loading factors

\begin{tabular}{lcccccc}
\hline $\begin{array}{l}\text { FEMA } \\
\text { flood zone }\end{array}$ & \multicolumn{1}{c}{ NFIP } & \multicolumn{3}{c}{ Study AAL results with different loading factors } \\
\cline { 2 - 7 } & $\begin{array}{c}\text { Average premium loss } \\
\text { cost per US\$1,000 }\end{array}$ & $\begin{array}{c}\text { Unloaded mean } A A L \\
\text { cost per US } \$ 1,000\end{array}$ & $\lambda=0.5$ & $\lambda=1$ & $\lambda=2$ & $\lambda=3$ \\
\hline A & $\$ 5.18$ & $\$ 5.51$ & $\$ 8.26$ & $\$ 11.02$ & $\$ 16.53$ & $\$ 22.03$ \\
X500/B & $\$ 4.76$ & $\$ 1.69$ & $\$ 2.54$ & $\$ 3.38$ & $\$ 5.07$ & $\$ 6.76$ \\
X/C & $\$ 1.68$ & $\$ 0.07$ & $\$ 0.11$ & $\$ 0.14$ & $\$ 0.21$ & $\$ 0.28$ \\
Travis County total & $\$ 3.39$ & $\$ 0.27$ & $\$ 0.40$ & $\$ 0.54$ & $\$ 0.81$ & $\$ 1.08$ \\
\hline
\end{tabular}

The premium charged will be $\left(1+\lambda_{\text {private }}\right) A A L$, where $\lambda_{\text {private }}$ is the loading factor a private insurer must charge on top of the pure premium. ${ }^{46}$

A recent paper by the Property Casualty Insurers Association of America ${ }^{47}$ provides some estimates of what some insurers might charge for such a loading. In addition to the cost of administering the insurance policy and settling claims (for which one can estimate a 50 per cent loading cost similar to what insurers currently charge the NFIP for their services), another 23 per cent must be added to reflect taxes ( 8 per cent) and the cost of capital (15 per cent). In other words, a 73 per cent loading cost $\left(\lambda_{\text {private }}=0.73\right)$ would be required if private insurers were to offer flood insurance ${ }^{47}$ If the insurer were to offer coverage only in high-risk zones, this cost of capital could be much higher, bringing the total loading factor to 100 or 200 per cent $\left(\lambda_{\text {private }}=1\right.$ or 2$)$. We thus examine scenarios with different loading factors, $\lambda_{\text {private }}=0.5,1,2$ and 3 . Table 6 presents the results of our premium comparison for Travis County with NFIP premiums having $\lambda_{\text {NFIP }}=0.50$ and private insurance using the average loss cost per US $\$ 1,000$ model results with the different loading factors just noted.

Table 6 reveals that a loading factor of nearly 200 per cent must be applied for the premiums charged by insurers in the X500 zone to be greater than the loaded NFIP values on average. This implies a tripling of the unloaded pure premium. In the $\mathrm{X} / \mathrm{C}$ zone, even applying a loading factor of up to 300 per cent we see that the loaded pure premium values are still significantly lower than the NFIP premiums on average. Overall, one sees that it would take a large loading factor for the private sector to charge more than the average US $\$ 3.39$ per US $\$ 1,000$ coverage currently charged by the NFIP on average for Travis County residents in these zones.

Table 7 presents the results of our full premium comparison for Galveston County using a similar methodology. Here the results are somewhat different, though. In V zones, insurers

\footnotetext{
46 This loading will depend on the characteristics of each firm, its portfolio diversification across geographies and types of risks (e.g. an insurer covering hurricane risks in coastal states might diversify its portfolio by selling flood risk insurance in Minnesota), correlation of risks regions, and hazards it covers (e.g. flood vs surge), whether there is some possible exposure to extreme events, whether it purchases some reinsurance and if so at what price, taxes it has to pay, administrative costs, etc. Note also that insurance regulators might not allow insurers to charge this premium because of pressure to keep premiums artificially low to please consumers.

${ }^{47}$ PCIAA (2011).
} 
Erwann Michel-Kerjan, Jeffrey Czajkowski and Howard Kunreuther Could Flood Insurance be Privatised in the United States?

Table 7 Galveston County full loaded premium comparison: NFIP and probabilistic flood model with various loading factors

\begin{tabular}{|c|c|c|c|c|c|c|}
\hline \multirow{2}{*}{$\begin{array}{l}\text { FEMA } \\
\text { flood zone }\end{array}$} & NFIP & \multicolumn{5}{|c|}{ Study AAL results with different loading factors } \\
\hline & $\begin{array}{c}\text { Average premium loss } \\
\text { cost per US\$1,000 }\end{array}$ & $\begin{array}{c}\text { Unloaded mean } A A L \\
\text { cost per US\$1,000 }\end{array}$ & $\lambda=0.5$ & $\lambda=1$ & $\lambda=2$ & $\lambda=3$ \\
\hline $\mathrm{V}$ & $\$ 14.17$ & $\$ 6.60$ & $\$ 9.89$ & $\$ 13.19$ & $\$ 19.79$ & $\$ 26.38$ \\
\hline A & $\$ 5.12$ & $\$ 6.31$ & $\$ 9.47$ & $\$ 12.63$ & $\$ 18.94$ & $\$ 25.26$ \\
\hline $\mathrm{X} 500 / \mathrm{B}$ & $\$ 1.92$ & $\$ 4.21$ & $\$ 6.32$ & $\$ 8.42$ & $\$ 12.64$ & $\$ 16.85$ \\
\hline $\mathrm{X} / \mathrm{C}$ & $\$ 1.44$ & $\$ 1.64$ & $\$ 2.46$ & $\$ 3.28$ & $\$ 4.92$ & $\$ 6.56$ \\
\hline Galveston County total & $\$ 2.90$ & $\$ 3.43$ & $\$ 5.14$ & $\$ 6.85$ & $\$ 10.28$ & $\$ 13.71$ \\
\hline
\end{tabular}

could impose a 100 per cent loading on top of the pure premiums and still charge less (US $\$ 13.19$ per US $\$ 1,000$ of coverage) than what the NFIP is currently charging (US\$14.17) on average. In the other zones, insurers would always charge more than the current average NFIP premium. In the A zone, we do find that the NFIP prices would remain on average much cheaper relative to what a private insurer would charge with virtually any loading factor. From this analysis it appears clearly that NFIP is largely overpricing properties in V zones and underpricing those that are located in less flood-exposed areas of Galveston on average.

\section{Discussion and conclusion}

\section{Summary of the research}

Benefiting from access to the NFIP portfolio and modern catastrophe flood models, this paper provides the first systematic analysis of the potential for private flood insurance in the United States to complement the current NFIP operation. We are indeed able to price flood insurance for individual single-family residences using these new modelling techniques.

Our findings demonstrate that in some areas, many homeowners are on average currently charged much higher premiums by this federal programme than what could be offered by a representative private insurer. In other flood-prone areas it would be hard for that private insurer to compete because the NFIP charges much less than the expected loss, or has a lower loading factor than that required for the insurer to be compensated for administrative and marketing expenses and cost of capital.

Taken together, these results offer several important insights into the debate on reforming flood insurance in the United States and in other countries (e.g. the United Kingdom). First, undertaking a microanalysis of the true exposure of residents to riverine and storm surge risks is important to determine the true risk-based pure premiums. One cannot simply aggregate risks per flood zones, as there is considerable heterogeneity in a given flood zone. It is important to determine the pure premium associated with a specific property in a given area that represents the risk associated with flooding, including the risk for truly catastrophic 
events. Our analysis should also provide important insight into the implementation of recent legislation in the United States: The Flood Insurance Reform Act of 2012 and the Homeowner Flood Insurance Affordability Act of 2014 both direct the NFIP to move to more risk-based premiums over time.

\section{Could a large private flood insurance market emerge in the U.S.?}

Our work demonstrates that the technology exists today to more accurately price flood risk. The deficit the NFIP now faces (US\$27 billion) has triggered an interest in the United States about (partial) privatisation of residential flood insurance. As mentioned earlier, some private flood insurance is sold, but this is a very small portion of the overall market. Whether there will be a significant shift towards much more private flood insurance being sold in the U.S. in the coming years remains to be seen. Of course, the decision by primary insurers to sell flood insurance at a given price depends on other factors that have not been analysed in this paper. These include but are not limited to: the ability of insurers to charge rates reflecting risk predicated on probabilistic modelling in a highly regulated market, special treatment to be given to those who cannot afford risk-based premiums, a strategy for transitioning existing NFIP policies into the private market, the management of high-risk repetitive loss locations, data sharing and accurate mapping. One also has to consider the possible correlation or diversification of flood risk with wind exposure from hurricanes or other risks in an insurer's portfolio.

Addressing these issues forms the basis for future research on how private insurers could be more active in providing flood coverage as a complement to the NFIP. For example, an analysis could be undertaken to better understand the appetite of primary insurers to participate in a private flood insurance market and what they believe are the major impediments in this regard. Some private insurers seem to have solved some of these issues and have begun to compete with the NFIP. For instance, Private Flood Insurance, a private insurer backed by Lloyd's now offers residential flood insurance in 16 states, most of them coastal, where the flood risk is typically high. On its website, the company advertises its product as "a simple alternative to FEMA flood insurance. While less expensive, our policies cover just as much as a FEMA National Flood Insurance Policy."

Privatisation of flood insurance could also be introduced by having the NFIP purchase partial reinsurance from private reinsurers or by issuing a catastrophe bond to cover unusually large flood losses such as those experienced from Hurricanes Katrina and Sandy. ${ }^{48}$ In Florida some exposure to severe wind damage from hurricanes has been transferred from the Florida Hurricane Catastrophe Fund (the state reinsurer) to international insurance and reinsurance markets. For instance, the FHCF issued a US\$2 billion bond in 2013 that would help it pay claims in the event of a major hurricane. ${ }^{49}$ Similar actions have been taken by the California Earthquake Authority for large-scale seismically related losses. ${ }^{50}$

\footnotetext{
${ }^{48}$ Michel-Kerjan (2010); Michel-Kerjan and Kunreuther (2011); GAO (2014).

${ }^{49}$ More details on the bond structure are available on the FHCF's website at: www.sbafla.com/fhcf/LinkClick . aspx? fileticket $=$ PpfxTWgmo $9 w \% 3 d \&$ tabid $=316 \&$ mid $=998$

${ }^{50}$ www.earthquakeauthority.com/UserFiles/File/Release/CEA\%20Second\%20Transformer\%20Deal\%20Release \%20FINAL.pdf
} 
While more private flood (re)insurance would help increase the number of residents with financial protection when the next large flood occurs, the government will still have an important role to play as reinsurer of last resort and providing technical and financial support for enforcing flood risk management regulations as discussed in a recent U.S. Government Accountability report on "Strategies for Increasing Private Sector Involvement). ${ }^{51}$

\section{Demand side considerations}

One open question is how these emerging dynamics on the supply side will impact the demand for flood insurance. A New York Times analysis published a few days after Hurricane Katrina in 2005 revealed that six out of ten homeowners in New Orleans had no flood insurance. ${ }^{52}$ As pointed out in Mayor Bloomberg's report following Hurricane Sandy in 2012, "New York City estimates that less than 20 per cent of residential buildings in areas inundated by Sandy had coverage through the NFIP" (Chapter 5, p. 97). ${ }^{1,53}$

This is confirmed by the academic literature on flood insurance. There is evidence that the demand for flood insurance is fairly price elastic. Prior studies show price elasticity of demand for residential flood insurance to be in the range of -0.62 to $-0.87^{54}$ to $-0.99,{ }^{55}$ and as high as -1.55 to -4.48 for flood insurance policyholders who benefit from subsidised rates by the federal government. ${ }^{56}$

It is not clear how large the demand for residential flood insurance will be in the coming years. A series of detailed analysis could be conducted that would complement earlier work in this arena, ${ }^{57}$ assessing household perceptions of flood risk under situations where premiums reflect risks, and monetary analysis of willingness to pay. ${ }^{58}$

Moreover, an in-depth analysis of the entire portfolio of the NFIP over the period 20002009 reveals that the median tenure of flood insurance is between two and four years implying that many homeowners purchase coverage when they buy their property but let the insurance lapse after a few years. ${ }^{59}$ This behaviour occurs even when homeowners are required to purchase flood insurance as a condition for a federally insured mortgage. Some banks and financial institutions have not enforced this regulation for at least two reasons: few of them have been fined and/or the mortgages are transferred to financial institutions on the secondary market in non-flood-prone regions of the country that have not focused on either the flood hazard risk or the requirement that homeowners may have to purchase this coverage.

In this regard, it is worth considering whether flood insurance should be required for everyone residing in a flood-prone area (as it is in France for instance), and if so, how to

${ }^{51} \mathrm{GAO}(2014)$.

${ }^{52}$ Bayot (2005).

${ }^{53}$ The numbers are believed to have been even lower for business; approximately 26,400 businesses with fewer than 50 employees were in the Sandy inundation zone in New York, but only 1,400 commercial NFIP policies were in effect when Sandy hit -95 per cent of them had no flood insurance.

${ }^{54}$ Landry and Jahan-Parvar (2011).

${ }^{55}$ Browne and Hoyt (2000).

${ }^{56}$ Landry and Jahan-Parvar (2011).

${ }^{57}$ Browne and Hoyt (2000); Kriesel and Landry (2004); Michel-Kerjan and Kousky (2010); Kousky (2011); Landry and Jahan-Parvar (2011).

${ }^{58}$ Botzen and van den Bergh (2012).

${ }^{59}$ Michel-Kerjan et al. (2012). 
enforce this requirement. One way to do this would be to tie flood insurance to the property rather than the individual, and entrust local communities to levy flood insurance premiums through real estate taxes.

Multi-year insurance contracts have been recently proposed as a complement or alternative to the standard one-year contract to ensure that homeowners retain their coverage. ${ }^{60}$ The design of such contracts must include a way to revise premiums that reflect risk due to short-term events (e.g. a major catastrophe such as Hurricane Katrina revealing unanticipated risks of storm surge damage) or longer term changes (e.g. higher losses due to sea level rise caused by climate change). A related issue is how to address the affordability concerns that could emerge as a result of charging everyone risk-based premiums. One possible approach is for FEMA to provide insurance vouchers to lowincome homeowners whose premiums increase due to the implementation of premiums reflecting risk. ${ }^{61}$

In closing, let us indicate that other catastrophe modelling firms as well as some large (re-)insurers are currently developing their own U.S. flood models, and several are planning to release these models in the near future. It would be instructive to compare the results of similar analyses using these different catastrophe models to see where they diverge and where they converge, and why. Having several flood models available on the market could also create competition that may lower the cost of using these. That would allow many more insurers, local, state and federal government agencies to use them, since they will be more easily affordable. ${ }^{62}$

This study has modelled riverine and storm-surge flood risk at the single-family residence level in two counties in Texas. It would be useful to expand this analysis to more states and countries facing potential flood damage. Given the restricted level of geographic detail associated with available NFIP data (no information on addresses is provided due to privacy concerns), it is not possible for us to do a residence-by-residence model comparison of flood insurance risk and pure premiums, including whether an existing policy is subsidised or not. A more detailed NFIP pure premium comparison of this nature would be useful to undertake. Finally, as noted in the introduction, several countries have developed private flood insurance markets. There are also studies under way in the Netherlands on the feasibility of a flood insurance market. ${ }^{63}$ It would be important to determine the lessons that can be learned from other countries that could be applied in modifying flood insurance in the United States.

\section{Acknowledgements}

The authors acknowledge partial funding by the National Science Foundation (grants \# SES-1062039 and SES-1061882), Swiss Re, the Travelers-Wharton Partnership for Risk Management and Leadership Fund, the U.S. Department of Homeland Security Center of Excellence (the Center for Risk and

\footnotetext{
${ }^{60}$ Jaffee et al. (2010).

${ }^{61}$ Kunreuther and Michel-Kerjan (2009); Kousky and Kunreuther (2014).

${ }^{62}$ We thank two referees for pointing out the possible barrier that large modelling cost would constitute. Catastrophe models for earthquakes and hurricanes are affordable and used by many organisations; flood catastrophe models will certainly become so as well.

${ }^{63}$ Botzen and van den Bergh (2008).
} 
Economic Analysis of Terrorism Events - CREATE) at USC, CRED at Columbia University, the Willis Research Network, the Zurich Insurance Foundation on community flood resilience and the Wharton Risk Center's Managing and Financing Extreme Events project.

We appreciate helpful comments on an earlier version of this paper from participants at the following conferences: Overby-Seawell Company Annual Conference (Kennesaw, GA); Intermediaries and Reinsurance Underwriters Association Fall Conference (Florham Park, NJ); Center for Insurance Policy and Research Summit (Atlanta, GA); Torrent Technologies 5th Annual Client Appreciation \& Education Seminar (Kalispell, MT); National Flood Conference, 29th Annual Meeting (Austin, TX); Reinsurance Association of America Current Issues Forum (Philadelphia, PA); National Flood Determination Association (Scottsdale, AZ); Southern Economic Association 81st Annual Meeting (Washington, DC); Managing and Financing Extreme Events Project 2011 Annual Meeting, Wharton Risk Management and Decision Processes Center (Philadelphia, PA); Hazards and Disasters Researchers Meeting (Broomfield, CO); 2011 Natural Hazards Workshop (Broomfield, CO).

\section{References}

Aerts, J.C. J.H., Botzen, W. J.W., Emanuel, K., Lin, N., de Moel, H. and Michel-Kerjan, E. (2014) 'Evaluating flood resilience strategies for costal megacities', Science 344(6183): 473-475.

Bayot, J. (2005) 'Payouts hinge on the cause of damage', New York Times, 31 August.

Bin, O., Kruse, J. and Landry, C. (2008) 'Flood hazards, insurance rates, and amenities: Evidence from the coastal housing market', The Journal of Risk and Insurance 75(1): 63-82.

Bin, O. and Polasky, S. (2004) 'Effects of flood hazards on property values: Evidence before and after Hurricane Floyd', Land Economics 80(4): 490-500.

Born, P. and Martin, W. (2006) 'Catastrophe modeling in the classroom', Risk Management and Insurance Review 9(2): 219-229.

Botzen, W. and van den Bergh, J. (2008) 'Insurance against climate change and flooding in the Netherlands: Present, future, and comparison with other countries', Risk Analysis 28(2): 413-426.

Botzen, W.J. and van den Bergh, J. (2012) 'Monetary valuation of insurance against flood risk under climate change', International Economic Review 53(3): 1005-1026.

Burby, R. (2001) 'Flood insurance and floodplain management: The US experience', Environmental Hazards 3(3): $111-122$.

Browne, M.J. and Hoyt, R.E. (2000) 'The demand for flood insurance: Empirical evidence', Journal of Risk and Uncertainty 20(3): 291-306.

City of New York (2013) A Stronger, More Resilient New York, New York, NY: New York City.

Congressional Budget Office (CBO) (2007) Value of Properties in the National Flood Insurance Program, Washington, DC: CBO.

Clark, M.J. (1998) 'Flood insurance as a management strategy for UK coastal resilience', The Geographical Journal 164(3): 333-343.

Czajkowski, J., Kunreuther, H. and Michel-Kerjan, E. (2013) 'Quantifying riverine and storm-surge flood risk by single-family residence: Application to Texas', Risk Analysis 33(12): 2092-2110.

Dixon, L., Clancy, N., Bender, B. and Ehrler, P. (2007) The Lender-Placed Flood Insurance Market for Residential Properties, Santa Monica, CA: RAND Corporation.

Federal Emergency Management Agency (FEMA) (2011) NFIP Reform: Phase III Report, from http://www.fema .gov/pdf/business/nfip/nfip_reform_phase_III_report.pdf, accessed 3 September 2014.

Gerdes, V. (1963) 'Insuring against flood peril', The Journal of Insurance 30(4): 547-553.

Government Accountability Office (GAO) (2008) Flood Insurance. FEMA's Rate-Setting Process Warrants Attention. GAO-09-12. Washington, DC: U.S. GAO.

Government Accountability Office (GAO) (2014) Flood Insurance: Strategies for Increasing Private Sector Involvement. GAO-14-127. Washington, DC: U.S. GAO.

Grossi, P. and Kunreuther, H. (eds) (2005) Catastrophe Modeling: A New Approach to Managing Risk, New York: Springer. 
Hall, T.M. and Sobel, A.H. (2013) 'On the impact angle of Hurricane Sandy's New Jersey landfall', Geophysical Research Letters 40(19): 2312-2315.

Hayes, T.L. and Spafford, D.R. (2008) Actuarial Rate Review, Washington, DC: Federal Emergency Management Agency.

Hayes, T.L., Spafford, D.R. and Boone, J.P. (2007) Actuarial Rate Review, Washington, DC: Federal Emergency Management Agency.

Jaffee, D., Kunreuther, H. and Michel-Kerjan, E. (2010) 'Long-term property insurance', Journal of Insurance Regulation 29(7): 167-187.

King, R.O. (2012) National Flood Insurance Program: Background, Challenges, and Financial Status, Washington, DC: Congressional Research Services, 7-5700, R40650, 1 July.

Kousky, C. (2010) 'Learning from extreme events: Risk perceptions after the flood', Land Economics 86(3): $395-422$.

Kousky, C. (2011) 'Understanding the demand for flood insurance', Natural Hazards Review 12(2): 96-110.

Kousky, C. and Kunreuther, H. (2014) 'Addressing affordability in the National Flood Insurance Program', Journal of Extreme Events 1(1): 1-28.

Kunreuther, H., Ginsberg, R., Miller, L., Sagi, P., Slovic, P., Borkan, B. and Katz, N. (1978) Disaster Insurance Protection: Public Policy Lessons, New York, NY: Wiley.

Kunreuther, H. and Michel-Kerjan, E. (2009) At War with the Weather: Managing Large-Scale Risks in a New Era of Catastrophes, Cambridge, MA: MIT Press.

Kriesel, W. and Landry, C. (2004) 'Participation in the National Flood Insurance Program: An empirical analysis for coastal properties', Journal of Risk and Insurance 71(3): 405-420.

Landry, C. and Jahan-Parvar, M. (2011) 'Flood insurance coverage in the coastal zone', The Journal of Risk and Insurance 78(2): 361-388.

Michel-Kerjan, E. (2010) 'Catastrophe economics: The National Flood Insurance Program', Journal of Economic Perspectives 24(4): 165-186.

Michel-Kerjan, E. and Kousky, C. (2010) 'Come rain or shine: Evidence on flood insurance purchases in Florida', The Journal of Risk and Insurance 77(2): 369-397.

Michel-Kerjan, E. and Kunreuther, H. (2011) 'Redesigning flood insurance', Science 333(6041): $408-409$.

Michel-Kerjan, E., Lemoyne de Forges, S. and Kunreuther, H. (2012) 'Policy tenure under the U.S. National Flood Insurance Program (NFIP)', Risk Analysis 32(4): 644-658, doi: 10.1111/j.1539-6924.2011.01671.x.

Overman, E.S. (1957) 'The flood peril and the Federal Flood Insurance Act of 1956', Annals of the American Academy of Political and Social Science 309(1): 98-106.

Pasterick, E.T. (1998) 'The National Flood Insurance Program', in H. Kunreuther and R.J. Roth Sr. (eds) Paying the Price: The Status and Role of Insurance Against Natural Disasters in the United States, Washington, DC: Joseph Henry Press, pp. 125-154.

Property Casualty Insurers Association of America (PCIAA) (2011) True Market-Risk Rates for Flood Insurance, PCI White Paper, June, Washington, DC.

SHELDUS (2011) www.webra.cas.sc.edu/hvri/products/sheldus.aspxc, accessed 12 August 2011.

Texas State Data Center (2011) www.txsdc.utsa.edu/, accessed 12 December 2011.

Thieken, A.H., Petrow, T., Kreibich, H. and Merz, B. (2006) 'Insurability and mitigation of flood losses in private households in Germany', Risk Analysis 26(2): 383-395.

U.S. Bureau of the Census (2011) 'Statistical abstract', from http://www.census.gov/compendia/statab/2011/ 2011edition.html, accessed 3 September 2014

von Ungern-Sternberg, T. (2004) Efficient Monopolies: The Limits of Competition in the European Property Insurance Market, Oxford: Oxford University Press.

Wetmore, F., Bernstein, G., Conrad, D., Larson, L., Plasencia, D., Riggs, R., Monday, J., Robinson, M.F. and Shapiro, M. (2006) An Evaluation of the National Flood Insurance Program: Final Report, Washington, DC: American Institutes for Research. 


\section{Appendix A}

\section{Definitions of FEMA flood zone designations}

Flood zones are geographic areas that the FEMA has defined according to varying levels of flood risk. These zones are depicted on a community's Flood Insurance Rate Map (FIRM) or Flood Hazard Boundary Map. Each zone reflects the severity or type of flooding in the area.

\section{Moderate- to low-risk areas}

In communities that participate in the NFIP, flood insurance is available to all property owners and renters in these zones:

\begin{tabular}{ll}
\hline Zone & Description \\
\hline B and X & $\begin{array}{l}\text { Area of moderate flood hazard, usually the area between the limits of the 100- } \\
\text { year and 500-year floods. Are also used to designate base floodplains of lesser } \\
\text { hazards, such as areas protected by levees from 100-year flood, or shallow } \\
\text { flooding areas with average depths of less than one foot or drainage areas less } \\
\text { than 1 square mile. }\end{array}$ \\
C and X & $\begin{array}{l}\text { Area of minimal flood hazard, usually depicted on FIRMs as above the 500- } \\
\text { year flood level. }\end{array}$ \\
\hline
\end{tabular}

High-risk areas

In communities that participate in the NFIP, mandatory flood insurance purchase requirements apply to all these zones:

\section{Zone Description}

A Areas with a 1 per cent annual chance of flooding and a 26 per cent chance of flooding over the life of a 30-year mortgage. Because detailed analyses are not performed for such areas; no depths or base flood elevations are shown within these zones.

AE The base floodplain where base flood elevations are provided. AE zones are now used on new format FIRMs instead of A1-A30 zones.

A1-30 These are known as numbered A zones (e.g, A7 or A14). This is the base floodplain where the FIRM shows a base flood elevation (old format).

AH Areas with a 1 per cent annual chance of shallow flooding, usually in the form of a pond, with an average depth ranging from 1 to 3 feet. These areas have a 26 per cent chance of flooding over the life of a 30-year mortgage. Base flood elevations derived from detailed analyses are shown at selected intervals within these zones. 


\section{Zone Description}

AO River or stream flood hazard areas, and areas with a 1 per cent or greater chance of shallow flooding each year, usually in the form of sheet flow, with an average depth ranging from 1 to 3 feet. These areas have a 26 per cent chance of flooding over the life of a 30-year mortgage. Average flood depths derived from detailed analyses are shown within these zones.

AR Areas with a temporarily increased flood risk due to the building or restoration of a flood control system (such as a levee or a dam). Mandatory flood insurance purchase requirements will apply, but rates will not exceed the rates for unnumbered A zones if the structure is built or restored in compliance with AR zone floodplain management regulations.

A99 Areas with a 1 per cent annual chance of flooding that will be protected by a federal flood control system where construction has reached specified legal requirements. No depths or base flood elevations are shown within these zones.

High-risk-coastal areas

In communities that participate in the NFIP, mandatory flood insurance purchase requirements apply to all these zones:

\begin{tabular}{ll} 
Zone & Description \\
\hline $\mathrm{V}$ & $\begin{array}{l}\text { Coastal areas with a 1 per cent or greater chance of flooding and an additional } \\
\text { hazard associated with storm waves. These areas have a } 26 \text { per cent chance of } \\
\text { flooding over the life of a } 30 \text {-year mortgage. No base flood elevations are } \\
\text { shown within these zones. }\end{array}$ \\
VE, V1-30 & $\begin{array}{l}\text { Coastal areas with a 1 per cent or greater chance of flooding and an additional } \\
\text { hazard associated with storm waves. These areas have a } 26 \text { per cent chance of } \\
\text { flooding over the life of a 30-year mortgage. Base flood elevations derived } \\
\text { from detailed analyses are shown at selected intervals within these zones. }\end{array}$ \\
\hline
\end{tabular}

\section{Appendix B}

\section{Additional information on the catastrophe model}

\section{Riverine flood hazard determination}

The flood frequency map quantifies the probability of any given location being flooded, and is constructed via three inputs-FEMA national flood risk zone maps, United States 
Geological Survey (USGS) National Hydro data set, and the USGS National Elevation data set. Flooding probabilities are defined for each 90×90 meter (m) area over the entire United States. Therefore, for any given property's latitude and longitude, the model will locate the associated $90 \times 90 \mathrm{~m}$ area and retrieve the assigned probability value.

The event return period is based upon 43 years' worth of monthly maximum discharge measurements from over 4,100 gauging stations located throughout the United States. To get the best possible capture of historical discharges, this data set was extended to outlets of each of the 24,000 drainage basins the U.S. counts, using a routing methodology that uses river networks, drainage area and precipitation as input parameters.

Then, Monte Carlo simulations were implemented to create an expanded probabilistic event return period set to extend the 43-year historical event return period set. These return period events have the same spatial and temporal correlations as the original ones, but unlike the original data, cover a time span of 10,000 years. Return periods of events are defined at a ZIP code resolution. Figures B1 and B2 illustrate the event return period distribution for Galveston and Travis Counties used in our model.

At a given property's latitude and longitude, the riverine flood inundation water depths from a collection of flood events are computed through an empirical relationship determined by the probability of flood occurrence combined with the flood intensity (event return period). Thus, the impact of flood events on a targeted geographical area (such as a county) can be quantitatively measured by the set of varying water depths across all flooded locations. For this study, the South Central USA geographical entity was used with 100,000 probabilistic events, with each event assigned an occurrence probability of 0.0001 . With the probability of flood occurrence in the ZIP code area and flood intensities (event return period) from the flood events that would have impact on the area, the flood depths can be determined through the empirical relationship.

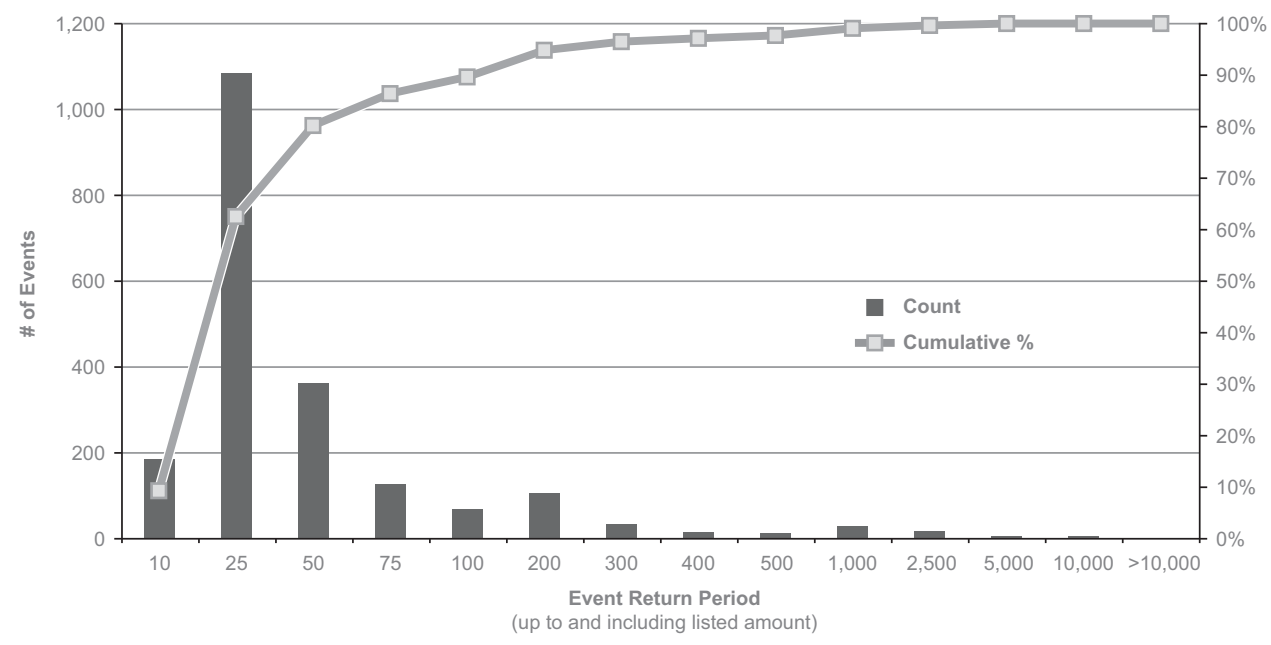

Figure B1. Galveston County riverine event distribution. 
The Geneva Papers on Risk and Insurance-Issues and Practice

28

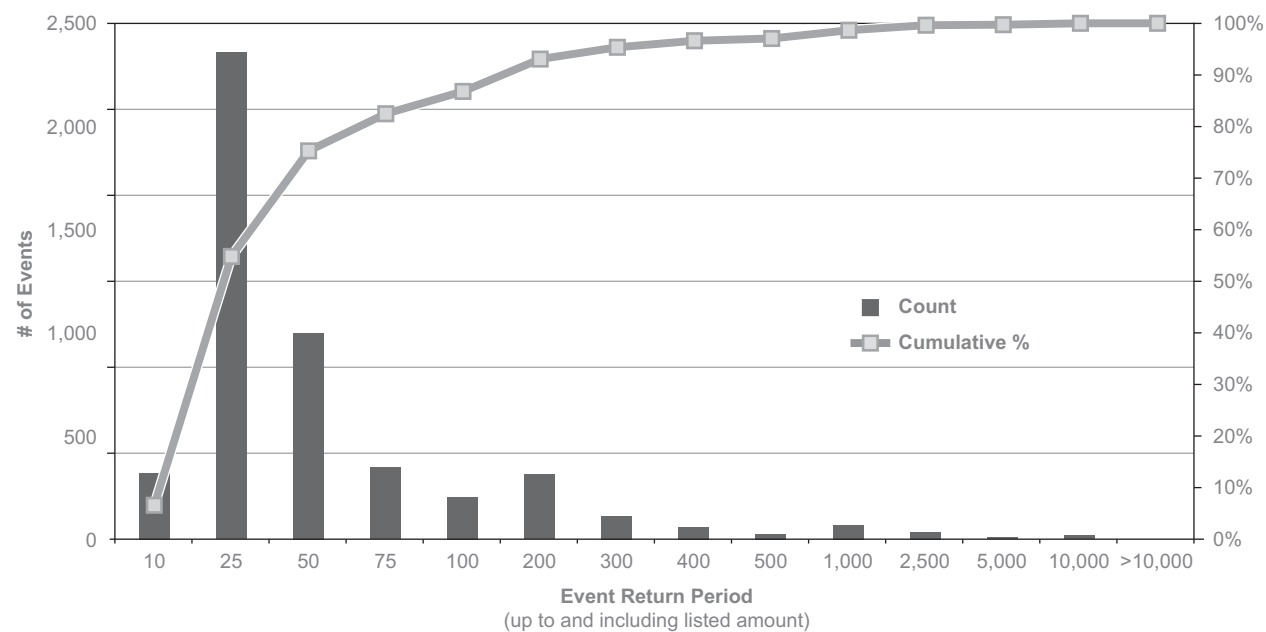

Figure B2. Travis County riverine event distribution.

Table B1 Hurricane event set: Saffir-Simpson category summary for Galveston County (storm surge)

\begin{tabular}{lcc}
\hline $\begin{array}{l}\text { Saffir-Simpson hurricane } \\
\text { category }\end{array}$ & $\begin{array}{c}\text { Number of events generated in our probabilistic approach } \\
\text { greater than or equal to category level }\end{array}$ & Cumulative \% \\
\hline 5 & 108 & 11.1 \\
4 & 196 & 20.2 \\
3 & 304 & 31.4 \\
2 & 470 & 48.5 \\
1 & 969 & 100.0 \\
& &
\end{tabular}

\section{Storm surge module}

Given this generated storm surge intensity from the stochastic event set, the storm surge height at a specific geographic location can be determined. Table B1 illustrates the distribution of the various hurricane categories for Galveston County generated in the model.

Inventory module

Table B2 summarises the type and property account we consider in the catastrophe model for Galveston County.

\section{Vulnerability module}

Vulnerability for flood hazards in the CoreLogic and Swiss Re models represents the relationship of water depth and mean damage ratio (MDR) on standardised categories of residential properties. Figure B3 illustrates normalised mean damage degrees per various 
Table B2 Summary of Galveston County total parcels by property types

\begin{tabular}{llr}
\hline Property code & Property code definition & Count \\
\hline 0 & Miscellaneous & 7 \\
10 & Single Family Residence/Townhouse & 98,636 \\
11 & Condominium (residential) & 143 \\
20 & Commercial & 5,686 \\
22 & Apartment & 1,875 \\
50 & Industrial & 146 \\
53 & Transport & 5 \\
54 & Utilities & 302 \\
70 & Agricultural & 2,415 \\
80 & Vacant & 42,690 \\
90 & Exempt & 4,751 \\
NA & NA & 3,668 \\
Total & & 160,324 \\
\hline
\end{tabular}

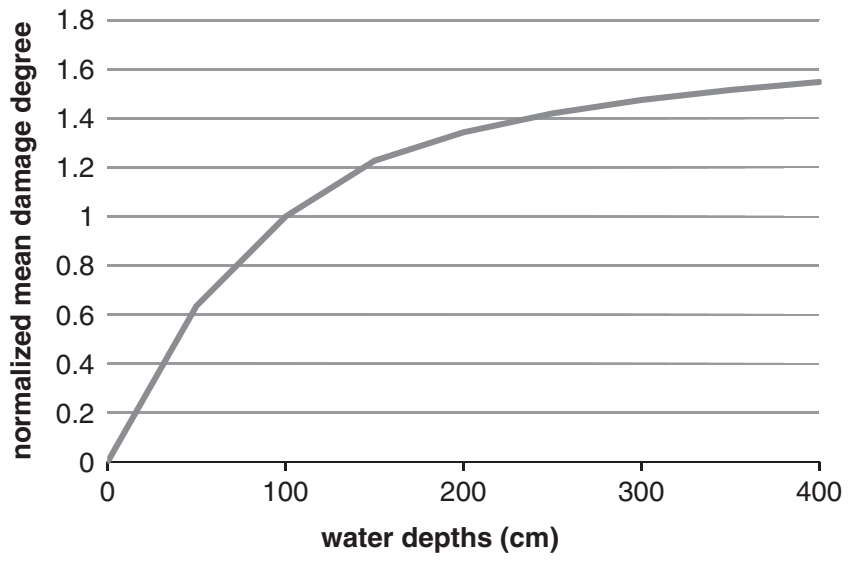

Figure B3. Indicative riverine flood vulnerability curve for mixed residential building.

water depths. Multiple sources of vulnerability data were used to generate the vulnerability curves in the model. The main source of data for residential risks was the detailed NFIP loss statistics compiled between 1978 and 2002, with over 850,000 single losses. To complete the vulnerability set, engineering methods of damage assessment and expert opinion were used as well.

\section{About the Authors}

Erwann Michel-Kerjan is the Executive Director of the Center for Risk Management and Decision Processes at the Wharton School of the University of Pennsylvania and teaches in Wharton MBA and executive programmes. Recipient of the prestigious Kulp-Wright award 
for the most influential contribution to risk management (At War with the Weather, MIT Press, with H. Kunreuther), he has authored over 100 publications on disaster risk financing, testified before the U.S. Congress and currently serves on the U.S. National Academies of Science's committee in charge of reviewing FEMA's flood insurance pricing methodology. He advises corporations, governments and international organizations including the World Bank, the World Economic Forum and the OECD (of which he chairs the Secretary- General's Advisory Board on these issues).

Jeffrey Czajkowski is a Senior Research Fellow at the Wharton Risk Management and Decision Processes Center serving as the Willis Research Network Fellow. His primary research fields are the economics of natural hazards and environmental economics, where his research has been published in leading risk, natural hazards, and environmental economics journals.

Howard Kunreuther is the James G. Dinan Professor of Decision Sciences and Business and Public Policy at the Wharton School, and Co-Director of the Center for Risk Management and Decision Processes, with a long-standing interest in ways that society can better manage low-probability, high-consequence events. He is a Fellow of the American Association for the Advancement of Science, a Distinguished Fellow of the Society for Risk Analysis and author of Insurance and Behavioral Economics: Improving Decisions in the Most Misunderstood Industry (with M. Pauly and S. McMorrow, Cambridge University Press, 2013). 